\title{
More Promoters and Less Detractors: Using Generalized Ordinal Logistic Regression to Identify Drivers of Customer Loyalty
}

\author{
En-Chung Chang ${ }^{1} \&$ Xiaomeng Fan ${ }^{2}$ \\ ${ }^{1}$ School of Business, Renmin University of China, Beijing, China \\ ${ }^{2}$ School of Economics and Management, Tsinghua University, Beijing, China \\ Correspondence: En-Chung Chang, 817 Mingde Business Building 59 Zhongguancun Street, Haidian District, \\ Beijing, 100872, China. Tel: 86-10-8250-0493. E-mail: ecchang@ruc.edu.cn
}

Received: May 8, $2013 \quad$ Accepted: May 24, $2013 \quad$ Online Published: August 6, 2013

doi:10.5539/ijms.v5n5p12 URL: http://dx.doi.org/10.5539/ijms.v5n5p12

\begin{abstract}
Many business organizations measure customer loyalty by using a question suggested by Reichheld (2003) - "likelihood to recommend the company to friend or colleague (LTR, $0=$ extremely unlikely, $10=$ extremely likely)". The LTR question can determine a customer's status as a detractor (LTR=0-6), a passively satisfied customer $(\mathrm{LTR}=7-8)$, or a promoter $(\mathrm{LTR}=9-10)$. Although this measure of customer status has been widely used in industry, no quantitative method so far has been introduced to analyze the underlying predictors of customer status as detractors, passively satisfied customers, or promoters. This study bridges the research gap by advocating Generalized Ordinal Logistic Regression (GOLR) as a viable statistical approach for identifying predictors for transforming customer status into a higher level (i.e., pulling customers out of the pool of detractors and driving them into the pool of promoters). Using online shopping as a research context, we found that GOLR outperformed traditional linear regression in identifying important predictors of customer status and in testing whether predictors have increasing or decreasing marginal effects on improving customer status to a higher level. Based on the results of GLOR, companies can make full use of the LTR question and design appropriate strategies for improvement.
\end{abstract}

Keywords: likelihood to recommend, net promoter score, generalized ordinal logistic regression, customer loyalty, marketing strategies

\section{Introduction}

In both the industry and academic realm of consumer research, customer loyalty is usually measured on a five or seven point Likert-like scale. Typical measurement items include "how likely are you to repurchase" and "how likely are you to recommend the company to others". Marketing practitioners and scholars then construct a regression model by using this sort of measurement as a dependent variable, and product/service performances in different facets as independent variables, in order to identify the important facets for enhancing customer loyalty. In 2003, Frederick Reichheld posited a new method to measure customer loyalty. Specifically, the method is to ask the LTR question: "How likely are you to recommend the company to your friend or colleague?" Customers respond to this question on an eleven point Likert-like scale ranging from extremely unlikely (0) to extremely likely (10). Responses to the LTR question help determine a customer's status as a promoter, passively satisfied customer, or detractor. Promoters are customers who respond to the LTR question with a 9 or 10. Passively satisfied customers are those who rate 7 or 8 on the scale. Detractors are those who respond with 0 through 6 . To help organizations achieve a better understanding of the LTR measure, Reichheld further proposed a net promoter score (NPS), which is calculated by subtracting the percentage of detractors from the percentage of promoters, and suggested that NPS should be the only number that companies need to grow because this score has been found to be strongly correlated with the growth rates in many industries (Reichheld, 2003)

The introduction of NPS to industries aroused debate among marketing researchers. On the one hand, some researchers challenged the claim that NPS is the most effective metric linking customer loyalty to company growth (Keiningham, Cooil, Andreassen, \&Aksoy, 2007). On the other hand, some leading companies like GE have successfully used the NPS metric to obtain insights on improving their products and services (Maddox, 2007; Teresko, 2006). The focus of this study, however, is neither to argue whether NPS is a superior metric to other loyalty measures nor to defend NPS as the only number that companies should attend to. Instead, we 
recognize important theoretical contributions of the LTR measure in classifying customers into promoters, passively satisfied customers, and detractors, and we also look beyond LTR or NPS scores to investigate how to improve organizations' performances in order to increase the number of promoters and reduce the number of detractors. As advocated by some researchers, NPS is only one piece of the equation (Cardis, 2008). Although it tells you how well you have done, it does not tell you why you did well or badly (Mitchell, 2008). Companies need to initiate actions after obtaining the NPS (Arussy, 2007).

To improve NPS, Reichheld suggested that companies hold direct conversations with detractors and promoters to probe for causes of dissatisfaction or delight, thereby developing improvement strategies accordingly (Reichheld, 2006). However, qualitative studies such as interviews or focus groups, which are based on a limited sample of customers, cannot generate representative feedback. Quantitative analysis based on consumer survey data can generate more reliable results for companies to identify root causes and make optimal customer-focused decisions (Owen \& Brooks, 2008). But to our knowledge, no quantitative method so far has been introduced to analyze the underlying predictors of customer status as detractors, passively satisfied customers, or promoters. This study bridges the research gap by advocating Generalized Ordinal Logistic Regression as a viable statistical approach for identifying operational elements that drive the transformation of customer status to a higher level (i.e., pulling customers out of the pool of detractors and driving them into the pool of promoters). Compared to traditional linear regression, this method can provide results that help companies leverage strengths for more accurate improvement strategies and more targeted marketing.

\section{Conceptual Background and Hypotheses}

\subsection{Ordinal Structure of Customer Status}

Loyalty to an object (e.g. a brand, store, service or company) is shown by favourable propensities towards that object (East, Gendall, Hammond, \& Lomax, 2005). These propensities may be behavioural or attitudinal. According to Reicheld (2003), likelihood to recommend is an accurate indicator of customer loyalty because when customers act as reference, they do more than indicate that they like the product offered by the company; they actually put their own reputation on the line. According their level of recommendation propensity, customers can be divided into promoters, passive satisfied customers and detractors. Promoters, passively satisfied customers, and detractors vary not only in their ratings of likelihood to recommend but also in their actual repurchasing and referral rates, which reflect the quality of the relationship between each customer status and the company. Promoters, who have the highest repurchase rates, account for more than 80 percent of the referrals. According to Reichheld, customers can be promoters only when they are highly engaged with the company in both the rational and the emotional dimensions (Reichheld, 2006). In the former dimension, customers believe in the superior value that the company offers. In the latter dimension, customers feel good about their relationship with the company and believe that the company will also satisfy their friends. The repurchasing and referral rates of passively satisfied customers, on the other hand, are usually lower than those of promoters by 50 percent or more. They think the goods or services offered by the company are acceptable, but they are not enthusiastic about them. They are very likely to switch once they get a better deal elsewhere. Finally, the detractors, who have the lowest repurchasing rate, account for more than 80 percent of negative word-of-mouth comments, which reduce the company's reputation and discourage new consumers. The above descriptions clearly indicate that customer status can be a variable with an ordinal nature; detractors, passively satisfied customers, and promoters actually represent an increasing level of customer-relationship quality, and the distances between adjacent statuses may not be equal.

According to previous studies, the relative impacts of various aspects of goods/services on customer satisfaction and loyalty change across levels of customer experiences. For example, researchers have identified that the impact of prompt responses to customer complaints is more pronounced in generating delight than in reducing disappointment, suggesting a nonlinear relationship between service responsiveness and customer evaluations (Estelami \& De Maeyer, 2002). Fan, Liu and Zhu also found nonlinear relationships between attribute-level performance and service outcomes: Improvement on spiritual care can bring increasing marginal returns on customers' likelihood to recommend hospitals (Fan, Liu, \& Zhu, 2009). In addition, Reichheld also suggested that reducing the percentage of detractors and increasing the percentage of promoters are two different processes (Reichheld, 2006). These studies imply that a goods/service facet may not have a uniform effect on escalating customer status to a higher level. That is, the ability of certain facets of performance to pull customers away from the pool of detractors may be significantly larger or smaller than its ability to drive customers to become promoters. Therefore, both the ordinal structure of the outcome variable customer status and potential increasing or decreasing impacts of goods/service facets on customer status validate the employment of Generalized Ordinal Logistic Regression to explore underlying predictors of customer status. 


\subsection{Advantages of Using Generalized Ordinal Logistic Regression}

Compared to traditional linear regression models, Generalized Ordinal Logistic Regression can provide more precise results regarding how to change customer status. First, Generalized Ordinal Logistic Regression shows the relative importance of independents on escalating customers to higher statuses, known as passively satisfied customers or promoters, who are located on the higher end of the 11-point measurement scale. In this case, the influences of independents on customers' LTR within the lower level of status-Detractors - tend to be reflected less in estimations of ordinal regression models. But such sacrifices are not undesirable, for it is more meaningful for companies to know whether certain facets of goods/services have significant impacts on converting customers to higher customer statuses than to know whether they have significant effects on improving the LTR score along the whole scale. In contrast, using LTR as the dependent variable and facets of goods/services as independent variables, linear regression models provide regression coefficients that reflect average magnitudes of impacts of independents on the dependent. Under the assumption of linearity, regression coefficients can be understood as relatively accurate estimations of impacts of independents on the dependent on every part of the scale. But if the linear assumption is violated, reported regression coefficients cannot truly reflect the weights of independents on specific parts of the LTR scale. For example, regarding the concern of businesses in knowing the abilities of certain goods/service facets to generate promoters, the results of linear regression tend to be biased because estimations can be undesirably attenuated by the effect of independents on moving LTR within the group of detractors. However, such details within the detractor group may not be of interest to companies. Even if customers can enhance LTR from 1 to 3 or from 3 to 5, they are still detractors, generating negative word-of-mouth for companies. Thus, we hypothesize that:

H1: Compared to a linear regression model that uses LTR as the dependent variable, Generalized Ordinal Logistic Regression using customer status as the dependent variable will have a greater ability to identify precise results regarding priorities for increasing the percentage of promoters and decreasing the percentage of detractors.

Second, Generalized Ordinal Logistic Regression can investigate the increasing or decreasing impact of an independent variable across levels of outcomes, thereby telling whether the independent has a greater ability in pushing customers away from detractors or converting them into promoters. This can be achieved through the Proportional Odds Model (POM) and the Partial Proportional Odds Models (PPOM), which are special cases of General Ordinal Logistic Regression (Williams, 2006). POM can be written in terms of cumulative distribution functions:

$$
P\left(Y_{i} \leq j\right)=F\left(X \beta_{j}\right)=\frac{1}{1+\exp \left(\alpha_{j}+X_{i} \beta_{j}\right)}, \mathrm{j}=1,2, \ldots, \mathrm{M}-1
$$

where $\mathrm{M}=$ total number of categories of the ordinal dependent variable;

$P(Y i \leq j)=$ probability that the individual $i$ will belong to category 1 to $j$;

$\mathrm{Xi}=$ matrix of explanatory variables.

POM assumes that slope coefficients ( $\beta$ s) for each independent variable are equal across M-1 equations. This assumption is known as the proportional odds assumption or parallel-line assumption. In our study, we use customer status as the dependent variable, which contains three categories ( $1=$ Detractors, $2=$ Passively Satisfied Customers and $3=$ Promoters). The predicted probabilities are:

$$
\begin{gathered}
P\left(Y_{i}=\text { Detractors } \mid X\right)=\frac{1}{1+\exp \left(\alpha_{1}+X_{i} \beta_{1}\right)} \\
P\left(Y_{i}=\text { Detractors \& Passively Satisfied Customers } \mid X\right)=\frac{1}{1+\exp \left(\alpha_{2}+X_{i} \beta_{2}\right)}
\end{gathered}
$$

According to the parallel-line assumption, $\beta_{1}$ in equation (1) and $\beta_{2}$ in equation (2) are correspondingly the same. In practice, however, the parallel-line assumption is often violated (Lall, Campbell, Walters, \& Morgan, 2002). That is, changes in a certain independent variable may not have uniform effects across levels of outcomes. To test the parallel-line assumption, a Wald test developed by Brant is usually applied to determine whether the coefficients for some independent variables are identical across the binary equations while the coefficients for other independent variables differ (Brant, 1990). Once the assumption is rejected, alternative models, such as PPOM, should be considered (Long \& Freese, 2006). As a special case of the general models, PPOM allows parameters where the parallel-line assumption has been violated to vary across the level of outcomes while others are constrained to be equal. For example, in the following equations with three explanatory variables, the 
$\beta s$ for independent variables $\mathrm{X} 1$ and $\mathrm{X} 2$ are constrained to be same across the two binary models, but the $\beta$ s for independent variable $\mathrm{X} 3$ are not, indicating that the parallel line assumption has been violated by X3:

$$
\begin{gathered}
P\left(Y_{i}=\text { Detractors } \mid X\right)=\frac{1}{1+\exp \left(\alpha_{1}+X 1_{i} \beta 1+X 2_{i} \beta 2+X 3_{i} \beta 3_{1}\right)} \\
P\left(Y_{i}=\text { Detractors \& Passively Satisfied } \mid X\right)=\frac{1}{1+\exp \left(\alpha_{1}+X 1_{i} \beta 1+X 2_{i} \beta 2+X 3_{i} \beta 3_{2}\right)}
\end{gathered}
$$

Using the PPOM, we can successfully distinguish the uniform, increasing, or decreasing effects that each goods/service facet may have in converting customers to a higher level of status. Such analysis cannot be achieved through traditional linear regression using LTR as the dependent variable. Hence, we hypothesize that

H2: The Partial Proportional Odds Model, a special case of Generalized Ordinal Logistic Regression, can detect whether each independent variable has a uniform effect in pushing customers away from detractors and in converting them to promoters. Linear Regression using LTR as the dependent variable cannot provide such information.

\subsection{Online Shopping as a Research Context}

No study so far has used Generalized Ordinal Logistic Regression modeling to predict customer status as promoters, passively satisfied customers, or detractors. Given that our study is the first of this kind, we decided to focus our initial investigation on a single industry. The online shopping industry was selected because of its rapid growth across developing countries and especially in China over the years. According to data issued by the Internet Society of China, online retail sales in China totaled 210.39 billion U.S. dollars in 2012, up 64.7 percent from the previous year. Alibaba, the world's largest online business-to-business trading platform for small businesses, has forecast that Chinese consumers will spend 265 billion U.S. dollars shopping online in 2013 and that China will overtake the US in online spending by then. Seeing the great potential in China's e-commerce market, many global companies are creating online channels to reach Chinese consumers. For example, Microsoft launched its flagship online store on Tmall.com, China's largest business-to-consumer website, to tap China's e-commerce boom. Neiman Marcus, the American luxury retailer, launched a website in China to test China's market and capitalize on the Chinese consumers' increasing demand for luxury goods. To succeed in China's online shopping market, it is important for companies to design their websites according to the likes and dislikes of Chinese consumers. What kinds of designs can turn Chinese consumers into promoters for a company? What kinds of offerings are necessary for preventing Chinese consumers from spreading negative comments about a company? The answers to these questions can help online companies initiate necessary changes in order to enlarge their pool of promoters and shrink the pool of detractors. In this research, we will answer these questions by investigating what facets of online shopping can change a customer status (promoters, passively satisfied customers, or detractors) through Generalized Ordinal Logistic Regression.

\section{Method}

\subsection{Data Source and Measurement}

The data used in this study were collected from a large university in Beijing, China. Three hundred and thirty-two university students $\left(M_{\mathrm{age}}=22,68.07 \%\right.$ females) filled out an online survey regarding their online shopping experiences. Participants are undegradute and graduate students in this university. Although university students may differ from general consumers in their beliefs and attitudes, they still make up a large proportion of Internet users (Lee \& Lin, 2005).

First, participants were asked to write down the three Internet apparel shopping websites with which they were most familiar. Then they were asked to think about their experiences with the first website they had listed and evaluate the website's performance on a list of features adopted from Kim, Kim and Kandampully (2009). The list consisted of thirty-nine features that cover six facets of website performance:

1) Convenience - website features that help customers find information with ease;

2) Customization - website features that recognize the individualized needs of customers and allow customers to personally tailor their choice of products, services, and shopping experience;

3) Trust Information - website features that ensure trust, security, and privacy issues when shopping online;

4) Communication - website features that provide buyers with the opportunity and ability to share opinions and information about products and services with the retailer through the site's communication attributes; 
5) Entertainment Value - website features that appeal to consumers' hedonic shopping orientation or enhance the entertainment value of shopping experiences;

6) Website Appearance - the general design or appearance of a website (i.e., background colors, logos, graphics on the main page, and borders or background patterns).

Participants were asked to indicate their experience with each of the thirty-nine features on a seven point Likert-like scale ranging from " $1=$ strongly disagree" to " $7=$ strongly agree". Finally, participants were asked to indicate how likely they were to recommend the website to their friends or colleagues on an eleven-point scale ranging from " $0=$ not at all likely" to " $10=$ extremely likely".

\subsection{Methods of Analysis}

\subsubsection{Exploratory Factor Analysis}

The first step was to conduct an exploratory factor analysis based on the 39 features of the shopping websites. We used a principle axis factor analysis and identified seven factors with eigenvalues greater than 1 . These seven factors were substantially similar to the six facets of shopping websites suggested by Kim et al. (2009), with the exception that the original "convenience" dimension was divided into two factors. One addressed the convenience in finding products (e.g., This site has clear and well-organized product categories). The other one, however, describes the convenient features for consumers to use after they locate the products they are interested in (e.g., The site provides timely information about product availability while I browse). In the following analysis, we separated these two dimensions of convenience and labeled them "Convenience in Finding Products" and "Convenience after Locating Products" respectively. After deleting cross-loading or low-loading (below .5) items, we obtained the final structure of items for each of the seven facets of website performance (see Table 1). Each facet was then measured using the average of items loaded on it.

\subsubsection{Generalized Ordinal Logistic Regression}

Customer likelihood to recommend the shopping website to others (LTR) was recoded into a new variable called Customer Status, for use as the dependent variable in Generalized Ordinal Logistic Regression. Specifically, Customer Status was coded as Detractors if the LTR was from 0 to 6; as Passively Satisfied Customers if the LTR was 7 or 8; and as Promoters if the LTR was 9 or 10. The seven identified facets of website performance were used as independent variables in Generalized Ordinal Logistic Regression.

A Proportional Odds Model was first constructed to investigate which facets of website performance would be significant in predicting Customer Status as Detractors, Passively Satisfied Customers, or Promoters. The model was developed and interpreted using odds ratios. The odds that an outcome is greater than versus less than or equal to $\mathrm{j}$ given $\mathrm{X}$ is defined as:

$$
\Omega_{>j \mid \leq j}(X)=\frac{P\left(Y_{i}>j \mid X\right)}{P\left(Y_{i} \leq j \mid X\right)}=\exp \left(\alpha_{j}+X_{i} \beta_{j}\right), \text { for } \mathrm{j}=1,2, \ldots, \mathrm{M}-1
$$

In our study regarding the driving forces of Customer Status, the odds of being at higher levels of Customer Status versus the lower levels can be expressed through the two following equations:

$$
\begin{aligned}
& \frac{\mathrm{P}\left(\mathrm{Y}_{\mathrm{i}}=\text { Promoters \& Passively Satisfied } \mid \mathrm{X}\right)}{\mathrm{P}\left(\mathrm{Y}_{\mathrm{i}}=\text { Detractors } \mid \mathrm{X}\right)} \\
& =\exp \left(\alpha_{1}+X_{\text {conv } 1} \beta_{\text {conv } 1}+X_{\text {enter } i} \beta_{\text {enter }}+X_{\text {web } i} \beta_{\text {web }}+X_{\text {trusti }} \beta_{\text {trust }}+X_{\text {commi }} \beta_{\text {comm }}+X_{\text {cust }} \beta_{\text {cust }}+X_{\text {conv } 2} ; \beta_{\text {conv } 2}\right)(\text { Note } 1) \\
& \mathrm{P}\left(\mathrm{Y}_{\mathrm{i}}=\text { Promoters } \mid \mathrm{X}\right) \\
& \overline{\mathrm{P}\left(\mathrm{Y}_{\mathrm{i}}=\text { Detractors \& Passively Satisfied } \mid \mathrm{X}\right)} \\
& =\exp \left(\alpha_{2}+X_{\text {conv } 1 ;} \beta_{\text {conv } 1}+X_{\text {enteri }} \beta_{\text {enter }}+X_{\text {web }} \beta_{\text {web }}+X_{\text {trusti }} \beta_{\text {trust }}+X_{\text {comm } i} \beta_{\text {comm }}+X_{\text {cust }} \beta_{\text {cust }}+X_{\text {conv } 2} \beta_{\text {conv } 2}\right)
\end{aligned}
$$

For a unit increase in an independent $X$, say $X_{\text {conv }}$, the odds of being at higher levels of Customer Status than at other lower levels of Customer Status are changed by the factor of $\mathrm{e}^{\beta \text { conv } 1}$, holding all the other independents constant (Garson, 2012). Following up with the Proportional Odds Model, a test of parallel regression assumption would indicate whether the beta coefficients for each independent in equations (5) and (6) are equal or not; that is, whether each facet of website performance has a uniform effect on pushing customers away from detractors and on converting customers to promoters. If the parallel regression assumption was violated, Partial Proportional Odds Model was applied by freeing the parameters where it was violated. Finally, to test the two hypotheses, results of Partial Proportional Odds Model were compared with the results of Linear Regression, 
using LTR measured on the original 11-point scale as the dependent variable. The said comparison was helpful for identifying whether a combination of the new concept (classifying the customers into three categories according to their response on LTR) and the new method (Generalized Ordinal Logistic Regression) would contribute additional value to the set of disciplines of NPS.

Table 1. Factor analysis

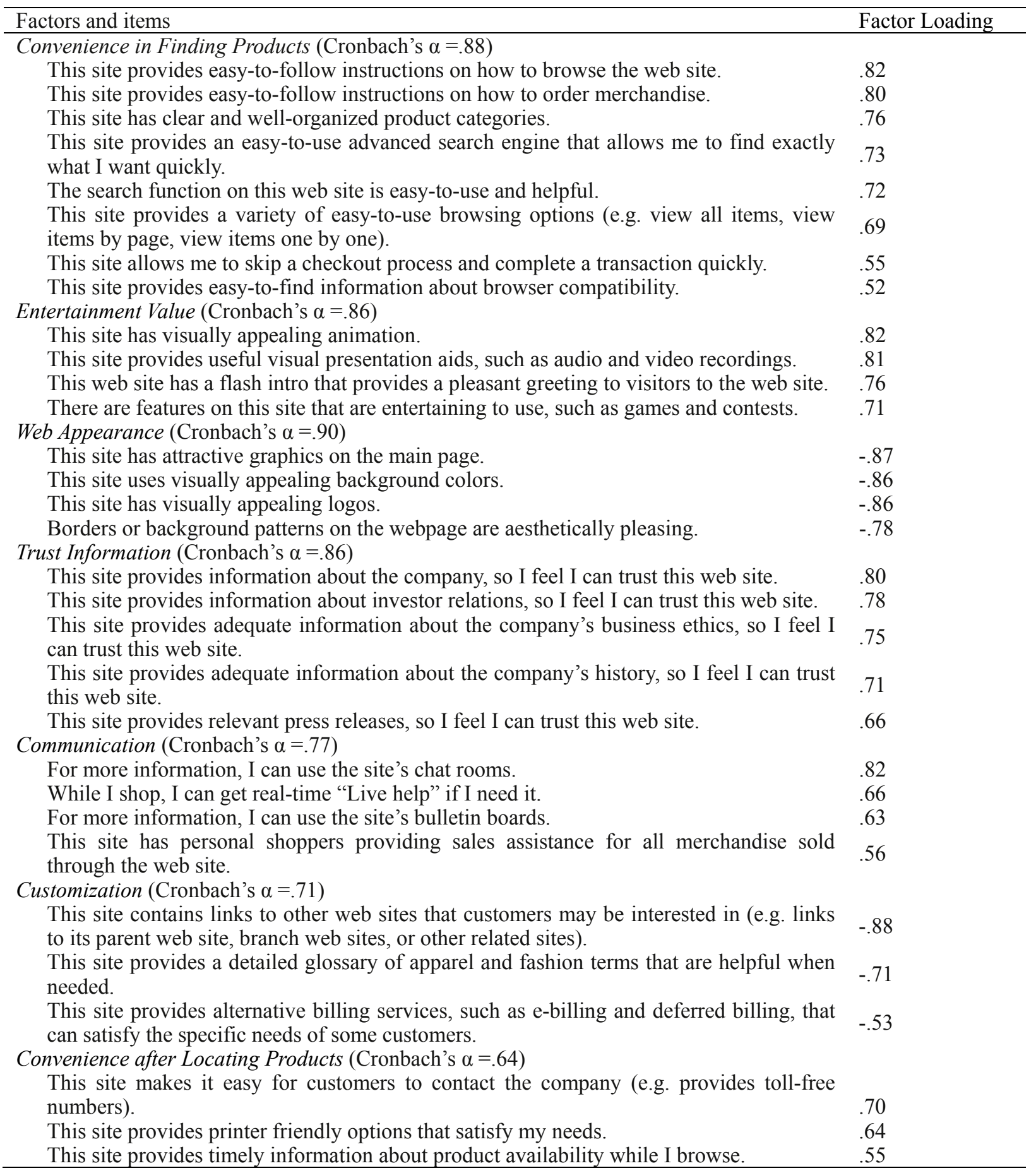

\section{Results}

\subsection{Descriptive Statistics}

Descriptive statistics of the dependent variable and independent variables are provided in Table 2. Generally, the 
sample consisted of nearly equal proportions of promoters (35.24\%), passively satisfied customers (33.13\%), and detractors $(34.64 \%)$. Females represented $68.07 \%$ of participants. Performances on seven facets of a website were indicated by the average ratings of related items. These scores were normally distributed and considered as continuous variables in the following analysis.

Table 2. Descriptive statistics

\begin{tabular}{|c|c|c|c|c|c|c|}
\hline Variable Description & $\begin{array}{l}\text { Measurement } \\
\text { Scale }\end{array}$ & Percent & Mean & S.D. & Min & Max \\
\hline \multicolumn{7}{|l|}{ Dependent Variable } \\
\hline \multirow{3}{*}{$\begin{array}{l}\text { Customer Status: } \\
\text { Classification of } \\
\text { customers according to } \\
\text { their likelihood to } \\
\text { recommend a website to } \\
\text { others (LTR) }\end{array}$} & $\begin{array}{l}\text { Detractors }(1) \\
\text { if } \mathrm{LTR}=0 \text { to } 6\end{array}$ & 34.64 & & & & \\
\hline & $\begin{array}{l}\text { Passively Satisfied (2) } \\
\text { if } \mathrm{LTR}=7 \text { to } 8\end{array}$ & 33.13 & & & & \\
\hline & $\begin{array}{l}\text { Promoters (3) } \\
\text { if } \mathrm{LTR}=9 \text { to } 10\end{array}$ & 35.24 & & & & \\
\hline \multicolumn{7}{|l|}{ Website Performances } \\
\hline Finding Products & \multicolumn{2}{|c|}{ Average Ratings of Related Items } & 5.21 & 1.08 & 1.25 & 7.00 \\
\hline [2] Entertainment Value & \multicolumn{2}{|c|}{ Average Ratings of Related Items } & 3.53 & 1.23 & 1.00 & 6.60 \\
\hline [3] Web Appearance & \multicolumn{2}{|c|}{ Average Ratings of Related Items } & 4.52 & 1.14 & 1.00 & 7.00 \\
\hline [4] Trust Information & \multicolumn{2}{|c|}{ Average Ratings of Related Items } & 4.42 & 1.24 & 1.00 & 7.00 \\
\hline [5] Communication & \multicolumn{2}{|c|}{ Average Ratings of Related Items } & 4.80 & 1.16 & 1.25 & 7.00 \\
\hline [6] Customization & \multicolumn{2}{|c|}{ Average Ratings of Related Items } & 4.41 & 1.20 & 1.00 & 7.00 \\
\hline $\begin{array}{l}\text { [7] Convenience after } \\
\text { Locating Products }\end{array}$ & Average Ratings of $\mathrm{Re}$ & tems & 4.02 & 1.31 & 1.00 & 7.00 \\
\hline
\end{tabular}

\subsection{Generalized Ordinal Logistic Regression: Proportional Odds Model and Partial Proportional Odds Model}

Proportional Odds Model regression of Customer Status on Website Performance indicated that both "Convenience in Finding Products" and "Trust Information" had significant effects on Customer Status, and "Communication" had a marginally significant effect on Customer Status. A Brant test showed that the parallel regression assumption had been violated by "Trust Information". That means that improving "Trust Information" had a significant nonlinear effect in promoting customers to a higher level of Customer Status. See Table 3 and Table 4 for results of the Proportional Odds Model and the test of parallel lines assumption.

Table 3. Proportional odds model (DV=Customer Status)

\begin{tabular}{lll}
\hline Independent Variables & Odds Ratio & $95 \% \mathrm{CI}$ \\
\hline Convenience in Finding Products & $2.25^{*}$ & {$[1.68,3.00]$} \\
Entertainment Value & .96 & {$[.77,1.20]$} \\
Web Appearance & .94 & {$[.73,1.21]$} \\
Trust Information & $1.30^{*}$ & {$[1.03,1.63]$} \\
Communication & $1.26 \dagger$ & {$[.99,1.60]$} \\
Customization & 1.05 & {$[.84,1.31]$} \\
Convenience after Locating Products & 1.14 & {$[.92,1.39]$} \\
\hline
\end{tabular}

Note:* $\mathrm{p}<0.05, \dagger \mathrm{p}=.06$. Numbers in parentheses are $95 \%$ confidence intervals of odds ratios. 
Table 4. Brant test of parallel regression assumption

\begin{tabular}{lll}
\hline Variables & $\mathrm{Chi}^{2}$ & $\mathrm{p}>$ chi2 \\
\hline All & 7.90 & .34 \\
Convenience in Finding Products & .07 & .79 \\
Entertainment Value & .01 & .91 \\
Web Appearance & .15 & .71 \\
Trust Information & 4.97 & .03 \\
Communication & 2.46 & .12 \\
Customization & .16 & .69 \\
Convenience after Locating Products & .62 & .43 \\
\hline
\end{tabular}

Note: For Trust Information, estimated coefficients from the binary models ("Passively Satisfied \& Promoters" vs. "Detractors", and "Promoters" vs. "Passively Satisfied \& Detractors") were significantly different: .10 vs. .43

According to the results of the Brant test, therefore, a partial proportional odds model (PPOM) was constructed by freeing the parameter of Trust Information and constraining others to be the same across the levels of outcomes.

$$
\begin{gathered}
\frac{\mathrm{P}\left(\mathrm{Y}_{\mathrm{i}}=\text { Promoters \& Passively Satisfied } \mid \mathrm{X}\right)}{\mathrm{P}\left(\mathrm{Y}_{\mathrm{i}}=\text { Detractors } \mid \mathrm{X}\right)} \\
=\exp \left(\alpha_{1}+X_{\text {conv } 1} \beta_{\text {conv } 1}+X_{\text {enteri }} \beta_{\text {enter }}+X_{\text {webi }} \beta_{\text {web }}+X_{\text {trusti }} \beta_{\text {trust } 1}+X_{\text {commi }} \beta_{\text {comm }}+X_{\text {custi }} \beta_{\text {cust }}+X_{\text {conv } 2 i} \beta_{\text {conv } 2}\right) \\
\frac{\mathrm{P}\left(\mathrm{Y}_{\mathrm{i}}=\text { Promoters } \mid \mathrm{X}\right)}{\mathrm{P}\left(\mathrm{Y}_{\mathrm{i}}=\text { Detractors \& Passively Satisfied } \mid \mathrm{X}\right)} \\
=\exp \left(\alpha_{1}+X_{\text {conv } 13} \beta_{\text {conv } 1}+X_{\text {enter }} \beta_{\text {enter }}+X_{\text {webi }} \beta_{\text {web }}+X_{\text {trusti }} \beta_{\text {trust } 2}+X_{\text {commi }} \beta_{\text {comm }}+X_{\text {cust }} \beta_{\text {cust }}+X_{\text {conv } 2 i} \beta_{\text {conv } 2}\right)
\end{gathered}
$$

The result of PPOM is provided in Table 5. Among the seven facets of website performances, "Convenience in Finding Products" was the only facet that continuously showed a significant effect in escalating customer status. This effect worked both in pulling customers out of the pool of detractors and in driving customers to become promoters. PPOM also identified significant contributions of the other two performance facets in escalating customer status. Specifically, improving the website's performance in Communication can significantly increase customers' odds ratios of being promoters or passively satisfied customers versus being detractors. But an improvement in Communication did not show a significant effect to drive customers to finally become promoters. Instead, a website's performance in providing "Trust Information" had a significant effect in enlarging the pool

\begin{tabular}{|c|c|c|c|c|}
\hline \multirow[b]{2}{*}{ Independent Variables } & $\begin{array}{l}\text { (1) } \\
\text { (Promoters \& } \\
\text { Customers) }\end{array}$ & assively Satisfied & $\begin{array}{l}\text { (2) } \\
\text { Promoters vs } \\
\text { (Detractors }\end{array}$ & assively Satisfied \\
\hline & $\begin{array}{l}\text { Odds Ratio } \\
\left(e^{\beta}\right)\end{array}$ & $95 \% \mathrm{CI}$ & $\begin{array}{l}\text { Odds Ratio } \\
\left(e^{\beta}\right)\end{array}$ & $95 \% \mathrm{CI}$ \\
\hline Convenience in Finding Products & $2.29 *$ & {$[1.67,3.16]$} & $2.20^{*}$ & {$[1.57,3.13]$} \\
\hline Entertainment Value & .95 & {$[.72,1.25]$} & .95 & {$[.73,1.23]$} \\
\hline Web Appearance & .92 & {$[.69,1.22]$} & .95 & {$[.72,1.27]$} \\
\hline Trust Information & 1.15 & {$[.88,1.51]$} & $1.48 *$ & {$[1.12,1.92]$} \\
\hline Communication & $1.45^{*}$ & {$[1.09,1.92]$} & 1.09 & {$[.82,1.46]$} \\
\hline Customization & 1.03 & {$[.79,1.35]$} & 1.08 & {$[.84,1.40]$} \\
\hline Convenience after Locating Products & 1.23 & {$[.95,1.58]$} & 1.07 & {$[.84,1.36]$} \\
\hline
\end{tabular}
of promoters, but the effect of providing "Trust Information" was not significant in shrinking the pool of detractors.

Table 5. Partial proportional odds model (DV=Customer Status)

Note: ${ }^{*} \mathrm{p}<.05$. Numbers in brackets are $95 \%$ confidence intervals of the odds ratios. 


\subsection{Linear Regression Model}

We also constructed a Linear Regression Model (LRM) in which the LTR measured on the 11-point scale was regressed on the seven facets of a website's performance. As indicated by Table 6, only the "Convenience in Finding Products" was significant in determining the LTR score. Performances in providing "Trust Information" and "Communication" were not found to be significant predictors of LTR.

Table 6. Linear regression model $(\mathrm{DV}=\mathrm{LTR})$

\begin{tabular}{lc}
\hline & Standardized Coefficient \\
\hline Convenience in Finding Products & $.41^{*}$ \\
Entertainment Value & .03 \\
Web Appearance & .02 \\
Trust Information & .08 \\
Communication & .05 \\
Customization & .02 \\
Convenience after Locating Products & .08 \\
\hline
\end{tabular}

Note: $* \mathrm{p}<.05$

\subsection{Hypotheses Testing}

A comparison of the two models is provided in Table 7. Both PPOM and LRM showed the significance of "Convenience in Finding Products" in influencing customers' likelihood to recommend. But the two models gave different information regarding the significance of other facets of website performance. Such differences were not surprising because the dependent variable LTR in LRM was treated as a continuous, interval variable, but the dependent variable Customer Status in PPOM reflected several critical ranges/points on the original LTR scale. Some independents may not be significant in improving the LTR score along the whole scale, but they may have significant abilities to convert customers across critical points - that is, to pull them out of the pool of Detractors, and to drive them into the pool of "Promoters". As seen in our study, although the average abilities of "Communication" and "Trust Information" to improve the LTR scores in general were not significant, these two facets of website performance still required attention from online retailers. "Communication" was found to be significant in shrinking the pool of detractors, and "Trust Information" was identified as important for enlarging the pool of promoters. However, such a strategic importance of "Communication" and "Trust Information" was likely to be neglected by LRM. According to the above stated findings, Hypothesis 1 is supported: Compared to traditional Linear Regression, Generalized Ordinal Logistic Regression Modeling can provide more precise results regarding priorities to improve Customer Status.

Table 7. A comparison of PPOM and LRM

\begin{tabular}{|c|c|c|}
\hline Comparisons & $\begin{array}{l}\text { PPOM } \\
\text { DV=Customer Status }\end{array}$ & $\begin{array}{l}\text { LRM } \\
\text { DV=Likelihood to Recommend (LTR) }\end{array}$ \\
\hline $\begin{array}{l}\text { Significance of The } \\
\text { Seven Facets of } \\
\text { Performances }\end{array}$ & $\begin{array}{l}\text { - "Convenience in Finding Products" } \\
\text { - "Communication" } \\
\text { - "Trust Information" }\end{array}$ & - "Convenience in Finding Products" \\
\hline $\begin{array}{l}\text { Priorities of } \\
\text { Improvement }\end{array}$ & $\begin{array}{l}\text { - For reducing detractors: } \\
\text { "Convenience in Finding Products" and } \\
\text { "Communication" } \\
\text { - For increasing promoters: } \\
\text { "Convenience in Finding Products" and "Trust } \\
\text { Information". }\end{array}$ & - "Convenience in Finding Products" \\
\hline Uniform Impacts & $\begin{array}{l}\text { - "Convenience in Finding Products" had a } \\
\text { significant, uniform effect in improving } \\
\text { Customer Status. } \\
\text { - "Communication" showed a decreasing } \\
\text { marginal ability to improve Customer Status. } \\
\text { - "Trust Information" showed an increasing } \\
\text { marginal ability to improve Customer Status. }\end{array}$ & $\begin{array}{l}\text { - "Convenience in Finding Products" } \\
\text { had a significant effect in improving } \\
\text { LTR. }\end{array}$ \\
\hline
\end{tabular}


The comparisons in Table 7 also indicate Generalized Ordinal Logistic Regression Modeling could test whether each aspect of website performance had consistent effects on pushing customers away from Detractors and on converting customers to Promoters. Results of PPOM suggest that "Convenience in Finding Products" had a uniform effect on improving customer status from Detractors, through Passively Satisfied Customers, and to Promoters. The effect of "Trust Information" on converting customers to promoters was significantly greater than its effect on pushing customers away from Detractors, showing an increasing ability of this facet in improving Customer Status. For "Communication", the effect on driving customers out of the pool of detractors was significant, but its effect on converting customers into promoters was not, therefore showing a decreasing effect in improving Customer Status. The above information could not be obtained through LRM. Therefore, Hypothesis 2 was supported: Generalized Ordinal Logistic Regression Modeling can detect whether each independent has a uniform effect in pushing customers away from detractors and in converting them to promoters, but Linear Regression using LTR as the dependent variable cannot provide such information.

\section{Conclusion and Discussion}

The results of this research offer important managerial implications to online retailers. First, the results clearly demonstrated that improving "Convenience in Finding Products" can make customers less likely to be Detractors and more likely to become Promoters for an online retailer. Meanwhile, improving the "Communication" function of the website has a significant effect in pushing customers away from Detractors, and providing sufficient amount of "Trust Information" has a significant effect in converting customers into Promoters. Therefore, online retailers aimed at enhancing their customer loyalty should first improve "Convenience in Finding Products", which includes the functions of a website in providing well-organized product categories and easy-to-use browsing options (e.g., view all items, view items by page, view items one by one, etc.). The next priorities of improvements go to "Communication" and "Trust Information". The "Communication" facet was more effective in shrinking the pool of Detractors. Therefore, online retailers who suffer from a large proportion of detractors should design and add effective communication features to their websites to ensure that customers receive real-time help and assistance from online channels such as chat-rooms. Good performance on "Communication" can prevent customers from spreading bad word-of-mouth to their friends and colleagues. On the other hand, the "Trust Information" facet was important for online retailers to enlarge their pool of promoters - the loyal customers who are most likely to recommend the company to other people. Improvement on this facet requires online retailers to provide adequate information on the company history, investor relations, business ethics, and relevant press releases so that customers can trust and feel secure when shopping on the websites. Such trust and security feelings can turn more customers into promoters for online retailers.

Earlier studies usually use linear regressions to explore effects of goods/services on customer satisfaction and loyalty. However, this research shows that using Generalized Ordinal Logistic Regression (GOLR) to explore Customer Status has several advantages over using the conventional method of linear regression models, in which customer overall satisfaction and loyalty were treated as dependent variables. First, it is more meaningful for companies to know whether certain aspects of goods/services have significant impacts on converting customers to higher levels of status (i.e., detractors, passively satisfied customers, and promoters) than to know whether they have significant effects on improving the LTR scores along the scale from extremely unlikely to extremely likely. GOLR in the special case PPOM may indicate a pattern of significance or effect magnitudes different from what can be found by using LRM. In such cases, companies are advised to refer to the result of GOLR, since it helps sharpen organizations' focus by discerning the effects of independents in escalating customer status across critical points. Second, GOLR can investigate whether an independent variable could have a uniform effect across levels of outcomes. Some independent variables may have a greater effect on pushing customers away from Detractors, and others may have a greater effect on developing customers into Promoters. An investigation of the increasing or decreasing marginal abilities of goods/services facets to promote customers to a higher level of status can facilitate companies to design a quality improvement strategy that addresses their real concerns. Using online shopping as a research context, we find that online retailers who are concerned about shrinking the pool of detractors should improve their website functions in "Conveniences in Finding Products" and "Communication", but online retailers who are struggling with how to improve the percentage of promoters in the customer base should address not only the "Convenience in Finding Products" facet but also the "Trust Information". However, such strategic priorities for improvement cannot be identified based on the results of traditional linear regression modeling, which only suggests the importance of "Convenience in Finding Products" in improving customers' likelihood to recommend.

\section{Limitations and Future Research}

One limitation of this study is using university students as reseach sample. University students had sufficient 
computer skills. Their concerns about online shopping services may differ from those of people who lack computer skills (e.g., people with lower education levels or elderly people). Future studies can address the moderating roles of computer skills and/or age of customers in investigating the relationship between performance facets and customer status, thereby addressing the unique concerns of specific customer groups.

This study uses online shopping as a research context. Future research can apply Generalized Ordinal Logistic Regression and the NPS concept in terms of three customer statuses in other industries to test the reliability of the methods advocated in this article. Such studies will build a solid foundation upon which to demonstrate the contributions of GOLR to the NPS paradigm, based on which businesses can develop more targeted marketing strategies and more accurate positioning in the market.

\section{Acknowledgements}

This research was supported by the National Natural Science Foundation of China (Project No. 71272154) and China Postdoctoral Science Foundation (Project No. 2012M510468).

\section{Note}

Note 1. $X_{\text {convli, }}, X_{\text {enteri, }}, X_{\text {webi }}, X_{\text {trusti, }}, X_{\text {commi, }}, X_{\text {custi }}$, and $X_{\text {conv2 } i}$ represent the independents Convenience in Finding Products, Entertainment Values, Web Appearance, Trust Information, Communication, Customization, and Convenience after Locating Products respectively.

\section{References}

Arussy, L. (2007). Imperfect scores. CRM Magazine, 11(10), 12.

Brant, R. (1990). Assessing proportionality in the proportional odds model for ordinal logistic regression. Biometrics, 46(4), 1171-1178. http://dx.doi.org/10.2307/2532457

Cardis, P. (2008). A score worth keeping. Professional Builder, 73(1), 21.

East, R., Gendall, P., Hammond, K., \& Lomax, W. (2005). Consumer loyalty: singular, additive or interactive. Australasian Marketing Journal, 13(2), 10-26. http://dx.doi.org/10.1016/S1441-3582(05)70074-4

Estelami, H., \& De Maeyer, P. (2002). Customer reactions to service provider overgenerosity. Journal of Service Research, 4(3), 205-216. http://dx.doi.org/ 10.1177/1094670502004003004

Fan, X., Liu, S., \& Zhu, M. (2009). An innovative approach examining the asymmetrical and nonlinear relationship between attribute-level performance and service outcomes. In A. L. McGill \& S. Shavitt (Eds.), Advances in consumer research (vol. 36, pp. 569-570). Duluth, MN: Association for Consumer Research.

Garson, G. D. (2012). Ordinal regression. Asheboro, NC: Statistical Associates Publishers.

Keiningham, T. L., Cooil, B., Andreassen, T. L., \& Aksoy, L. (2007). A longitudinal examination of net promoter and firm revenue growth. Journal of Marketing, 71(3), 39-51. http://do.doi.org/10.1509/jmkg.71.3.39

Kim, J. H., Kim, M., \& Kandampully, J. (2009). Buying environment characteristics in the context of e-service. $\begin{array}{llll}\text { European Journal of } & \text { Marketing, }\end{array}$ http://dx.doi.org/http://dx.doi.org/10.1108/03090560910976438

Lall, R., Campbell, M. J., Walters, S. J., \& Morgan, K. (2002). A review of ordinal regression models applied on health-related quality of life assessments. Statistical Methods in Medical Research, 11(1), 49-67. http://dx.doi.org/10.1191/0962280202sm271ra

Lee, G. G., \& Lin, H. F. (2005). Customer perceptions of e-service quality in online shopping. International Journal of Retail \& Distribution Management, 33(2), 161-176. http://dx.doi.org/10.1108/09590550510581485

Long, J. S., \& Freese, J. (2006). Regression models for categorical dependent variables using stata (2nd ed.). College Station, TX: STATA Press.

Maddox, K. (2007). Research spurs debates over net promoter score. B to B, 92(11), 3-33.

Mitchell, A. (2008). The only number you need to know does not add up to much. Marketing Week, 31(9), $22-23$.

Owen, R., \& Brooks, L. L. (2008). Answering the ultimate question: How net promoter can transform your business. San Francisco, CA: John Wiley and Sons, Jossey-Bass.

Reichheld, F. F. (2003). The one number you need to grow. Harvard Business Review, 81(12), 46-54. 
Reichheld, F. F. (2006). The ultimate question: Driving good profits and true growth. Boston, MA: Harvard Business School Press.

Teresko, J. (2006). GE asks the ultimate question. Industry Week/IW, 255(6), 52.

Williams, R. (2006). Generalized ordered logit/ partial proportional odds models for ordinal dependent variables. The Stata Journal, 6(1), 58-82.

\section{Copyrights}

Copyright for this article is retained by the author(s), with first publication rights granted to the journal.

This is an open-access article distributed under the terms and conditions of the Creative Commons Attribution license (http://creativecommons.org/licenses/by/3.0/). 